\title{
Assessment of Aesthetic Quality on Soil and Water Conservation Engineering Using the Scenic Beauty Estimation Method
}

\author{
Szu-Hsien Peng ${ }^{1, *(1)}$ and Ke-Tsung Han ${ }^{2}$ \\ 1 Department of Spatial Design, Chienkuo Technology University, Changhua City 500, Taiwan \\ 2 Department of Landscape Architecture, National Chin-Yi University of Technology, \\ Taichung 41170, Taiwan; kthan@ncut.edu.tw \\ * Correspondence: shpeng@cc.ctu.edu.tw; Tel.: +886-4-711-1111 (ext. 2256)
}

Received: 22 February 2018; Accepted: 29 March 2018; Published: 30 March 2018

check for updates

\begin{abstract}
Taiwan has rich natural landscapes, but the sensitive geology and concentrated rainfall have resulted in frequent sediment hazards. Thus, various stream control works are established in watersheds to secure midstream and downstream citizens' lives and properties. Taking care of slope safety and natural landscapes has become a primary issue for soil and water conservation engineering. The scenic preference beauty estimation method (SBE) in psychophysics, which was proposed by Daniel and Boster in 1976, is utilized herein to evaluate the scenic aesthetics of stream control engineering in watersheds. It aims to discuss various landscape factors (water body, vegetation) in the aesthetic preference and differences of various artificial structures in a watershed under people's psychology. First, pictures and images related to soil and water conservation engineering are collected, and an in-situ investigation is performed to determine the pictures and images for discussion and design of the relevant questionnaire. The scenic aesthetics evaluation results are standardized with RMRATE, a computer program for analyzing rating judgments, of the United States Department of Agriculture, and then transformed into SBE values to compare the difference of various engineering structures in scenic aesthetics. The results reveal that flowing waterscape elements and the coverage of vegetation on the surrounding artificial structure volume in images present positive effects on the public overall scenic aesthetics. This study is expected to provide engineering designers with reference for considering a design integrating engineering structure with natural landscapes.
\end{abstract}

Keywords: landscape quality; scenic beauty estimation method (SBE); soil and water conservation engineering

\section{Introduction}

Soil and water conservation refers to controlling water and soil loss, protecting, improving, and legally applying slopeland water and soil resources, and maintaining and enhancing land productivity for thoroughly developing the economic and social benefits of water and soil resources [1]. In addition to establishing the comprehensive technology development of a good ecological environment, soil and water conservation continuously promotes the ecological engineering concept of stream control, emphasizes flexible techniques and the research and development of materials, stresses on the balance of engineering and the natural environment, and conserving or recovering the natural environment of streams as much as possible to maintain biodiversity [2].

Taiwan has rich natural landscapes, which in addition to ecological diversity, offer the possibilities of stress relief and relaxation. Nevertheless, the sensitive geology of slopeland and the concentrated rainfall in the country have resulted in frequent sediment hazards. Accordingly, various soil and water 
conservation engineering structures have been established at appropriate locations on the slopeland to secure midstream and downstream citizens' lives and properties as well as public construction safety [3]. The establishment of such structures often changes natural landscapes to affect the original ecological and psychological functions [4]. Therefore, taking care of the slopeland safety and the natural landscapes has become a primary issue for soil and water conservation engineering.

According to the regulations of the "National Environment Policy Act" of 1969, "Forest and Rangeland Renewable Resource Planning Act" of 1974, and "National Forest Management Act" of 1976, landscape architects have to take systematic considerations of scenic aesthetics into account in the decision-making process because scenic aesthetics is a shared resource, which should be protected like other public assets, such as soil, water, air, and sun [5-12].

However, laws can simply act as guidance. They do not propose any definite and practicable methods for landscape assessment. Therefore, architects and managers must independently develop new assessment methods or analyze existing visual resource analyses [6]. In this case, many landscape resource assessment methods have emerged, such as the "phenomenological model" [13], "ecological model" [14], "formal aesthetic model" and "psychophysical model" [15], "landcover model" [16], "prospect-refuge theory" [17], "landtype hypothesis" [18], and "psychology model" [19].

Landscape assessment is generally divided into four types [20-24], namely expert school, psychophysical school, cognitive school, and empirical school. The psychophysical school advocates that scenic aesthetics resulted from the interaction of the viewers' perception and cognition and assumes the close preference of the public for natural landscapes; that is, the higher beauty appears on the higher preference. It could operate environmental physical characteristics for the experimental design and analyze the relationship between environmental physical factors and preference; hence, it is often used by planning and design units [25].

Compared to buildings, bridges, and other constructions, designers also have a considerable emphasis on aesthetic design in addition to safety considerations. Censorship systems that allow both safety and aesthetic design to be considered even exist. However, soil and water conservation engineering is in a natural area, and its landscape assessment should be considered to maintain the scenic beauty of the natural environment. At present, no relevant mechanism considers aesthetics in the design of soil and water conservation works in Taiwan. As a result, no principles are followed in the aesthetic design for these works, often leading to a sense of incompatibility between the visual effects of the engineering structures and the environment.

This study intends to explore a suitable landscape assessment method through a literature review. The scenic beauty estimation method (SBE), which is commonly used in the psychophysical school, is introduced herein to study various soil and water conservation structures. The scenic aesthetics evaluation results are standardized with RMRATE of the United States Department of Agriculture (USDA) and transformed to the SBE to study the difference of various engineering structures in scenic aesthetics. At the end of this study, one is expected to understand different types of structures or scenic aesthetics of landscape elements. The thinking process for the aesthetic design of soil and water conservation engineering in a watershed could be continuously studied, such that the design principles would show a better reference value.

\section{Literature Review}

\subsection{Introduction of the Scenic Beauty Estimation Method Classification System}

Various SBE methods seem complicated, but could be discriminated with development logic, progressive time frame, and methodological approach. In terms of the development logic, some of the abovementioned SBE methods originated from theories, while others might have come from empirical research. Table 1 organizes the classification systems of the SBE method in the development logic.

As regards a progressive time frame, such SBE methods could be divided into three phases according to the development time. In the first phase (i.e., 1967-1971), the SBE method depended 
on the planners' and landscape architects' intuitive judgment. In the second phase (1971-1976), the evaluation model was changed into a calculation with complicated statistics. In the third phase (i.e., 1973-present), the viewers' landscape preference was emphasized [26,27]. The abovementioned eight SBE methods were classified according to these time phases. Moreover, a time overlap can be observed in the three phases. The same model might appear in different versions that some models are classified into two different phases. Table 2 shows the classification of the SBE methods according to the progressive time frame.

Table 1. Classification of the scenic beauty estimation method development logic.

\begin{tabular}{cc}
\hline Theoretical Type & Empirical Type \\
\hline Phenomenological model (e.g., Lynch [13]) & Formal aesthetic model (e.g., Litton [28]) \\
Ecological model (e.g., McHarg and Mumford [14]) & Psychophysical model (e.g., Shafer et al. [15]) \\
Prospect-refuge theory (e.g., Appleton [17]) & Landcover model (e.g., Jackson and Zube [16]) \\
Land use assumption (e.g., Balling and Falk [18]) & \\
Psychology model (e.g., Kaplan and Kaplan [19]) & \\
\hline
\end{tabular}

Table 2. Classification of the scenic beauty estimation method progressive time frame.

\begin{tabular}{ccc}
\hline Phase I (1967-1971) & Phase II (1971-1976) & Phase III (1973-Current) \\
\hline $\begin{array}{c}\text { Phenomenological model } \\
\text { (e.g., Lynch [13]) }\end{array}$ & $\begin{array}{c}\text { Psychology model } \\
\text { (e.g., Kaplan et al. [29]) }\end{array}$ & $\begin{array}{c}\text { Prospect-refuge theory } \\
\text { (e.g., Appleton [17]) }\end{array}$ \\
\hline $\begin{array}{c}\text { Formal aesthetic model } \\
\text { (e.g., Litton [28]) }\end{array}$ & $\begin{array}{c}\text { Psychophysical model (e.g., } \\
\text { Daniel and Boster [30]) }\end{array}$ & $\begin{array}{c}\text { Psychophysical model } \\
\text { (e.g., Daniel and Boster [30]) }\end{array}$ \\
\hline $\begin{array}{c}\text { Landcover model } \\
\text { (e.g., Jackson and Zube [16]) }\end{array}$ & $\begin{array}{c}\text { Land use assumption } \\
\text { (e.g., Balling and Falk [18]) }\end{array}$ \\
\hline $\begin{array}{c}\text { Ecological model (e.g., McHarg } \\
\text { and Mumford [14]) }\end{array}$ & $\begin{array}{c}\text { Psychology model } \\
\text { (e.g., Kaplan and Kaplan [19]) }\end{array}$ \\
\hline & $\begin{array}{c}\text { Fuzzy logical system model (e.g., } \\
\text { Peng and Tang [31]) }\end{array}$ \\
\hline
\end{tabular}

The abovementioned SBE methods could be divided into description, evaluation, and preference according to different methodological approaches. The description model simply measures or describes environmental characteristics. The evaluation model judges the quality of landscapes. The preference model displays the viewers' subjective preference for landscapes [32,33]. Table 3 presents the classification results.

Table 3. Classification of the scenic beauty estimation method methodological approach.

\begin{tabular}{ccc}
\hline Description & Evaluation & Preference \\
\hline $\begin{array}{c}\text { Phenomenological model } \\
\text { (e.g., Lynch [13]) }\end{array}$ & $\begin{array}{c}\text { Formal aesthetic model } \\
\text { (e.g., Litton [28]) }\end{array}$ & $\begin{array}{c}\text { Psychophysical model } \\
\text { (e.g., Shafer et al. [15]) }\end{array}$ \\
\hline $\begin{array}{c}\text { Prospect-refuge theory } \\
\text { (e.g., Appleton [17]) }\end{array}$ & Landcover model & $\begin{array}{c}\text { Psychology model (e.g., Kaplan } \\
\text { and Kaplan [19]) }\end{array}$ \\
\hline $\begin{array}{c}\text { Land use assumption (e.g., Jackson and Zube [16]) } \\
\text { Balling and Falk [18]) }\end{array}$ & $\begin{array}{c}\text { Ecological model (e.g., McHarg } \\
\text { and Mumford [14]) }\end{array}$ & \\
\hline
\end{tabular}

The preference SBE in psychophysics, which was proposed by Daniel and Boster [30], was applied herein to evaluate the scenic aesthetics of stream control engineering in a watershed. The SBE may be the earliest objective method to quantify the scenic beauty of the landscape. It is assessed using photos and provides a simple and scientifically quantifiable method of evaluation. The scenic evaluation 
result is standardized with RMRATE of the USDA and transformed into an SBE to understand the difference of various engineering structures in scenic aesthetics.

\subsection{Scenic Beauty Estimation}

As an abstract concept, scenic aesthetics is studied with a qualitative method. In the period of the psychophysical school, previous studies [30,34,35] developed SBE as the source for quantitative analysis of scenic aesthetics. The SBE method is the experiment of psychophysiology to evaluate forest scenic aesthetics. The idea originated from the stimulus-response model of the behavioral psychology school improved according to the signal detection method and the Thurston-scaling models. It took the evaluators' perceived scenic aesthetics allocation to represent the viewers' preference for a landscape or beauty [25].

In the experiment process, the subjects were shown some representative color slides (stimuli) and scaled the respondence according to preference. The scale of 0-9 presented low-to high-quality scenic aesthetics [36]. The statistical method was used to standardize the evaluation acquired with distinct evaluation criteria to solve the possible differences caused by different evaluation gauge bases used by evaluators. The method is expected to accurately measure the public relative perceived preference for different landscapes. The randomly sampled perception evaluation would become the normal distribution when the number of samples is large enough. In short, the SBE method presents the following advantages and drawbacks [30].

(1) Advantages

- An intangible value of resources could be included in the quantitative assessment. Combining psychology and the technique of statistics, the individual subjective judgment of managers and planning designers is excluded. However, the public "perceived preference" for different landscapes is applied to reflect the viewers' perceived preference for landscapes.

- Regarding the test of validity, the SBE method proves that the subjects' evaluation of the slides or pictures randomly taken in the base is similar to the in-situ evaluation that manpower and time could be reduced.

- In terms of the retest reliability, the SBE method proves that the pictures taken in the same base but at different times, appear with high consistency, excluding the factor of special events. The method apparently shows high reliability.

- In addition to the forest landscape assessment, the SBE method is applied in various landscapes to test applicability. The result proves high reliability and validity.

- The evaluation error that resulted from different aesthetic concepts is removed.

- $\quad$ The SBE index could be applied to large-coverage landscape management.

- The evaluation result of the landscape factors could help understand the positive/negative effects on recreation users for the reference of future business management.

(2) Drawbacks

- Whether the selected landscape samples could represent general landscapes is controversial.

- When taking landscapes from pictures, the photographers' photography skills and angles would affect the evaluation result.

- The evaluation coverage and the special areas cannot be defined from the pictures.

- Whether viewers refer the evaluation preference for landscapes to perception or cognition cannot be distinguished.

- The coefficient acquired from the analysis result lacks definite explanations, which would change with the people and is comparatively subjective.

In the assessment process, the subjects' assessment was not only simply influenced by the perceived stimuli, but also by the interaction between the perceived stimuli and the applied evaluation 
criteria. The model assumed that the subjects, after receiving the stimuli, would transform the stimuli into a subjective impression through the perception process; that is, subjects must compare with certain evaluation criteria or other perceived stimuli to show the assessment. With either of the assessment methods, the subjects' respondence of selection, sorting, or evaluation, could merely provide indicators for being transformed into a psychological-scale evaluation with proper mathematical processes, where the SBE proposed by Daniel and Boster [30] exhibits the most representativeness [25].

An "object-centered" $S B E$ value is common, where many observers evaluate the same object, and each object is merely evaluated once. A repeated evaluation is acquired herein from different observers' evaluations. In this case, the $S B E$ could be acquired when the number of observers is more and the number of objects is few or single, or the preference of all objects is required [30]. First, the average $Z$ of each object was calculated assuming that all observers' cognition of objects and the evaluative criteria have a normal distribution. Second, the average $Z$ of the "datum line" object selected by the researcher was calculated to adjust the origin of the $S B E$ scale. The original $S B E$ of each object was acquired by deducting the calculated $Z$ of each object from the average $Z$ of the "datum line" and multiplying by 100. The calculation is as follows [30]:

$$
M Z_{i}=\frac{1}{m-1} \sum_{k=2}^{m} \Phi^{-1}\left(C P_{i k}\right)
$$

where: $M Z_{i}=$ the average $Z$ of object $i ; \Phi^{-1}=$ the function transforming cumulative probability $C P_{i k}$ to $Z ; C P_{i k}=$ the ratio of an observer's evaluation of object $i$ being $k$ or higher than $k$; and $m=$ evaluation level.

$$
S B E_{i}=\left(M Z_{i}-B M M Z\right) \times 100,
$$

where: $S B E_{i}=$ the original $S B E$ of object $i ; M Z_{i}=$ the average $Z$ of object $i$; and $B M M Z=$ the average $Z$ of the "datum line".

The original $S B E$ of different groups might contain distinct origins or/and metric; hence, the original SBE is divided by the standard deviation of the average $Z$ of the "datum line." The metric difference caused by different cognitions of objects could be removed after being adjusted with standardization. The calculation is shown as follows:

$$
S B E_{i}^{*}=S B E_{i} / B S D M Z
$$

where: $S B E_{i}^{*}=$ the standardized $S B E$ of object $i$, and $B S D M Z=$ the standard deviation of the average $Z$ of the "datum line."

\section{Materials and Methods}

The SBE method in psychophysics, which was proposed by Daniel and Boster [30], was applied herein to evaluate scenic aesthetics. From domestic and international soil and water conservation engineering, 16 images were selected for the slides. The subjects were requested to proceed with the preference evaluation according to the engineering structure and the environmental scenic aesthetics in the slides. The scenic aesthetics evaluation results were standardized with RMRATE of the USDA and transformed into an SBE to compare the difference of engineering structures in scenic aesthetics.

Before the formal evaluation, the slides were quickly browsed to adjust the individual evaluation standard. For the formal evaluation, each slide was projected for $16 \mathrm{sec}$ and evaluated from 0 (extremely dislike) to 9 (extremely like). After filing the basic data, the preference evaluation was processed with RMRATE of the USDA [37,38]. Taking the average of 16 images as the baseline, the $Z$ score of each image was transformed into an SBE. The implementation details were described below. 


\subsection{Research Location}

Photographs were taken at four sampled locations, namely (1) Taiwan Forestry Research Institute Lianhuachih Research Center; (2) Guanshi Stream in Zhongpu Township, Chiayi County; (3) Tainan Xinhua Livestock Research Institute; and (4) Tainan Gueidan Hot Spring. The Taiwan Forestry Research Institute Lianhuachih Research Center, with an altitude of 2100-3370 m above sea level, is in Wucheng Village, Yuchih Township, Nantou County, Taiwan. With the temperate climate, the vegetation was a forest vegetation of a natural coniferous forest and a coniferous/broad-leaved forest. The research institute mainly engages in studying watershed water and intermediate high-altitude forest ecology in the high mountains of central Taiwan.

The Guanshi Stream located in Zhongpu Township, Chiayi, Taiwan was affected by Typhoon Morakot, which resulted in a large-scale landslide that buried roads and destroyed bridges and revetment. Regulation works were done there. Sand-control detention dams, with the function of sand control and detention, were allocated in the regulation works to control the discharge volume in the downstream bottleneck section. A new technique, called the branch block revetment, was used for engineering and improved according to the local conditions. This technique was a challengeable and innovative technique used to achieve the goals of water and soil conservation, natural ecology conservation, and disaster prevention and control.

The Tainan Xinhua Livestock Research Institute established in 1940, is in Xinhua District, Tainan City, Taiwan. It contains seven branches in Xinchu, Yilan, and in other areas. It is in charge of the livestock research in Taiwan. After the establishment of the Ministry of Agriculture, it would be renamed the Ministry of Agriculture Livestock Research Institute. Many landscape detention pools related to soil and water conservation engineering have been established around the area for a stable water source.

The Gueidan Hot Spring is the first hot spring in Gueidan, Tainan City, Taiwan built by the government to promote the preciousness of hot spring resources, market Gueidan Hot Spring, create the brand image of Gueidan Hot Spring, develop the tourism resources in Nanxi areas, and enhance the development of the Gueidan Hot Spring area. A tourism service center and an approximately $4000 \mathrm{~km}^{2}$ open space with recreation decks and relevant soil and water conservation engineering can also be found in the park.

\subsection{Shooting Environment Setting}

A sunny day in the shot environment was chosen, such that a uniform quality of the pictures can be achieved, and the effect of climate changes on the visual perception can be removed. The first shooting was held in September 2014 in the Taiwan Forestry Research Institute Lianhuachih Research Center and in December in the Guanshi Stream in Zhongpu Township, Chiayi County. The second shooting was done in February 2015 in the Tainan Xinhua Livestock Research Institute and the Tainan Gueidan Hot Spring at 10:00-16:00. The shooting was stopped at noon (i.e., 11:00-13:00) to avoid different beauty preferences caused by the strong sun. Moreover, human activity in the pictures would affect the visual preference; hence, human activity and animals were avoided.

\subsection{Picture Sampling}

The pictures were corrected with Photoshop (PS), the image-processing software developed and issued by Adobe Systems, to obtain a uniform precision of the pictures and remove the effect of climate on the visual preference. The sampled pictures were processed the sunshine and ray with the software for the questionnaire survey.

Pictures with a close proportion were selected. Traditional and ecological methods were used to pick the pictures. The proportion of traditional and ecological methods was finally used to decide which pictures would be included. A total of 16 pictures were selected in Table 4 . 


\subsection{Questionnaire Design}

With a close-end questionnaire structure, the contents are described as follows:

Question 1: Picture aesthetics: The subjects judge the aesthetics in the picture according to personal perception.

Question 2: Integration of structure with the natural environment in the picture: The integration of the artificial structures with the surrounding natural landscapes in the picture is evaluated.

Question 3: Preference of waterscape in the picture: The subjects would evaluate the pictures with waterscape by the preference for the flowing waterscape.

Question 4: Visual richness of picture: The subjects, according to personal perception, judge the color and the visual richness of the surrounding landscape.

Question 5: Preference for the shape of the structure in the picture: The subjects evaluate the shape of the artificial structures in the pictures according to personal preference.

Question 6: Perceived safety of the structure in the picture: The subjects evaluate the perceived safety of structures in the pictures (only from psychological experience).

The basic data of the subjects contained gender, age, occupation, studied lessons, and understanding of the function of structures in the pictures.

\subsection{Questionnaire Survey}

The questionnaire was preceded on sites and through the Internet on 14-15 April 2015. The selected digital pictures were shown to the subjects through slides for evaluation. One slide was evaluated at a time without comparing the slides. The test processes and contents were explained as follows:

(1) The subjects were arranged for the test in a classroom equipped with a projector and a white screen, where the digital pictures were shown.

(2) The subjects were explained the questionnaire contents, purpose of the test, evaluation scale, and personal data filling-in.

(3) The subjects were requested to evaluate with personal preference and intuition without thinking for too long nor judging with photography skills or aesthetics.

(4) The pictures were projected with the speed of $3 \mathrm{~s} /$ picture for the subjects fast-browsing the contents.

(5) The subjects then viewed the projected pictures with a speed of $16 \mathrm{~s} /$ picture and fill in the score for beauty and other questions according to intuitive judgment. The subjects were also reminded to pay attention to the number of pictures and the relevant questions.

A free online questionnaire system, called mySurvey, was used to collect the Internet questionnaire on 14-28 April 2015. A total of 105 valid copies were collected for this study.

\section{Results and Discussion}

\subsection{SBE Evaluation Result}

In this study, 51 students of Chienkuo Technology University were selected as the control group for the evaluation, and 105 copies of Internet questionnaires were used. All the subjects, including 51 students (control group) and 105 Internet questionnaire respondents, were asked to evaluate 16 images for processing with RMRATE of the USDA. The average of all images was used as the baseline $(S B E=0)$. Table 4 presents the preliminary statistics and the SBE transformation result. Meanwhile, the control group and the Internet questionnaire were used to compare the differences in the landscape assessment. A paired sample $t$-test was utilized for the test (Table 5). A $p$-value $>0.05$ with a two-tailed test was chosen under the significance of $5 \%$. The $S B E$ value of the landscape assessment of 16 pictures did not 
exhibit remarkable differences between the control group and the Internet questionnaire survey. As a result, the $S B E$ was again calculated and sequenced for all the samples (Table 4).

Table 4 shows at least four types of soil and water conservation engineering: check dam (No. 01, No. 12, No. 13, No. 15 and No. 16), ground sill (No. 03, No. 09, No. 10 and No. 14), revetment (No. 02, No. 08 and No. 11), detention pond (No. 04, No. 06 and No. 07) and grassed waterways (No. 05). Some of them were built using traditional methods (e.g., the main material mainly made of concrete). Some belonged to ecological engineering, which used natural materials and vegetation to integrate with the environment. The section that follows will discuss the assessment results of these images in further detail.

\subsection{Comparison between the Traditional Method and the Ecological Method}

Three images each with the highest and lowest SBEs were selected by analyzing the questionnaire results through the preference SBE method in psychophysics. The top three images were No. 06 ecological detention pool, No. 14 groundsill work, and No. 11 revetment with the ecological method. A rich waterscape, not too big structure volume, harmony with the environment, and conformity to the aesthetic principle of structure integrating with the environment are the common points of the three images. Referring to question 2 (Figure 1), the scores of the three pictures also ranked top three. Apparently, a higher integration of structures with nature would receive better scores on the aesthetic evaluation. Moreover, the proportion of the waterscape was larger in the three pictures; hence, the scores for question 3 were higher (Figure 2). Apparently, waterscape aesthetics could affect the score [39]. The structure in No. 14 is groundsill work, whose structure form is common, without a large of surrounding vegetation. Nevertheless, the adequate flow and the large proportion of water body in the picture made the focal landscape largely enhance the overall scenic aesthetics [40,41]. Meanwhile, the scenic aesthetics of the river bank with a medium flow was higher than that with a low flow [42].

Table 4. Landscape assessment results of 16 images.

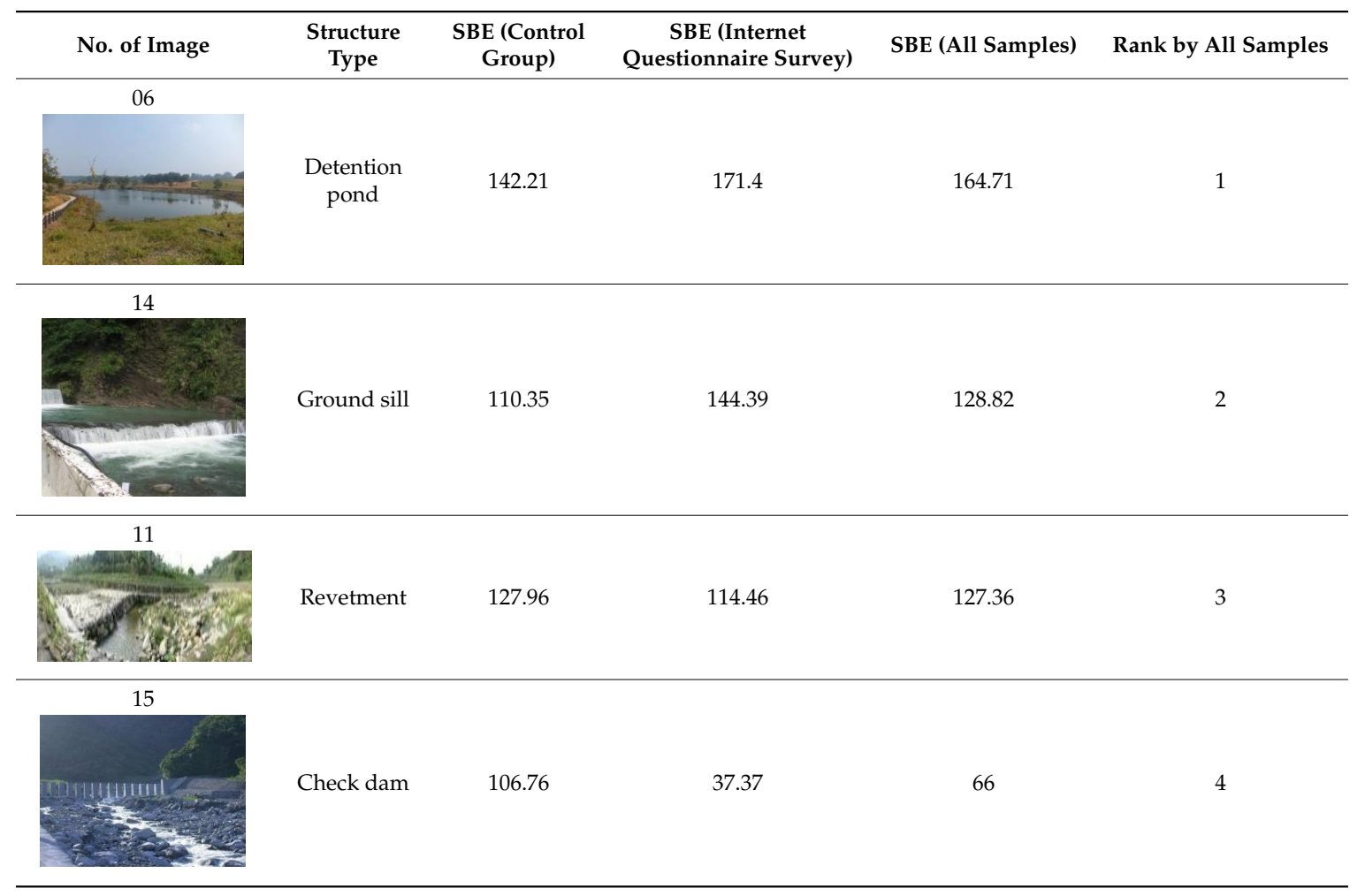


Table 4. Cont.

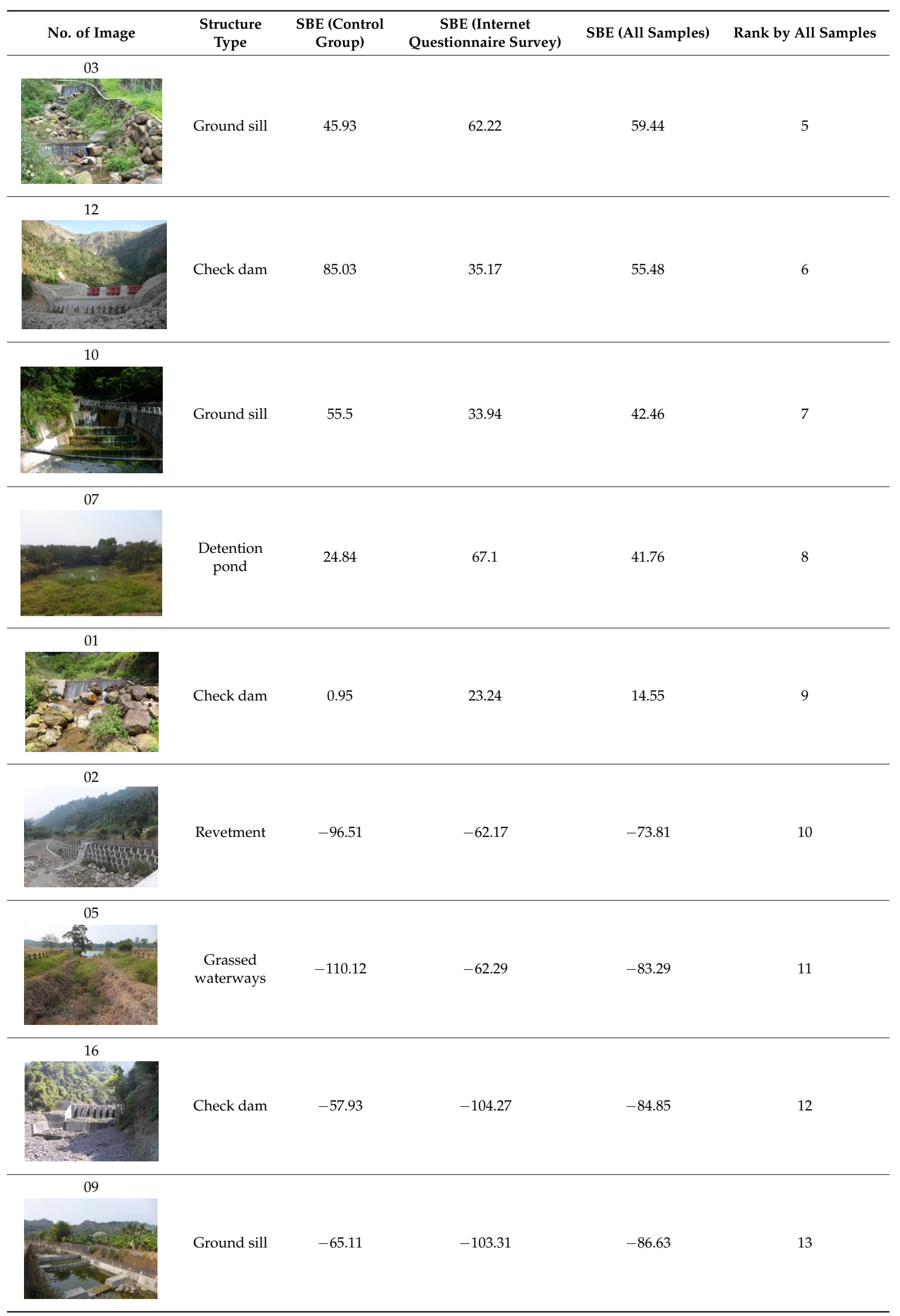


Table 4. Cont.

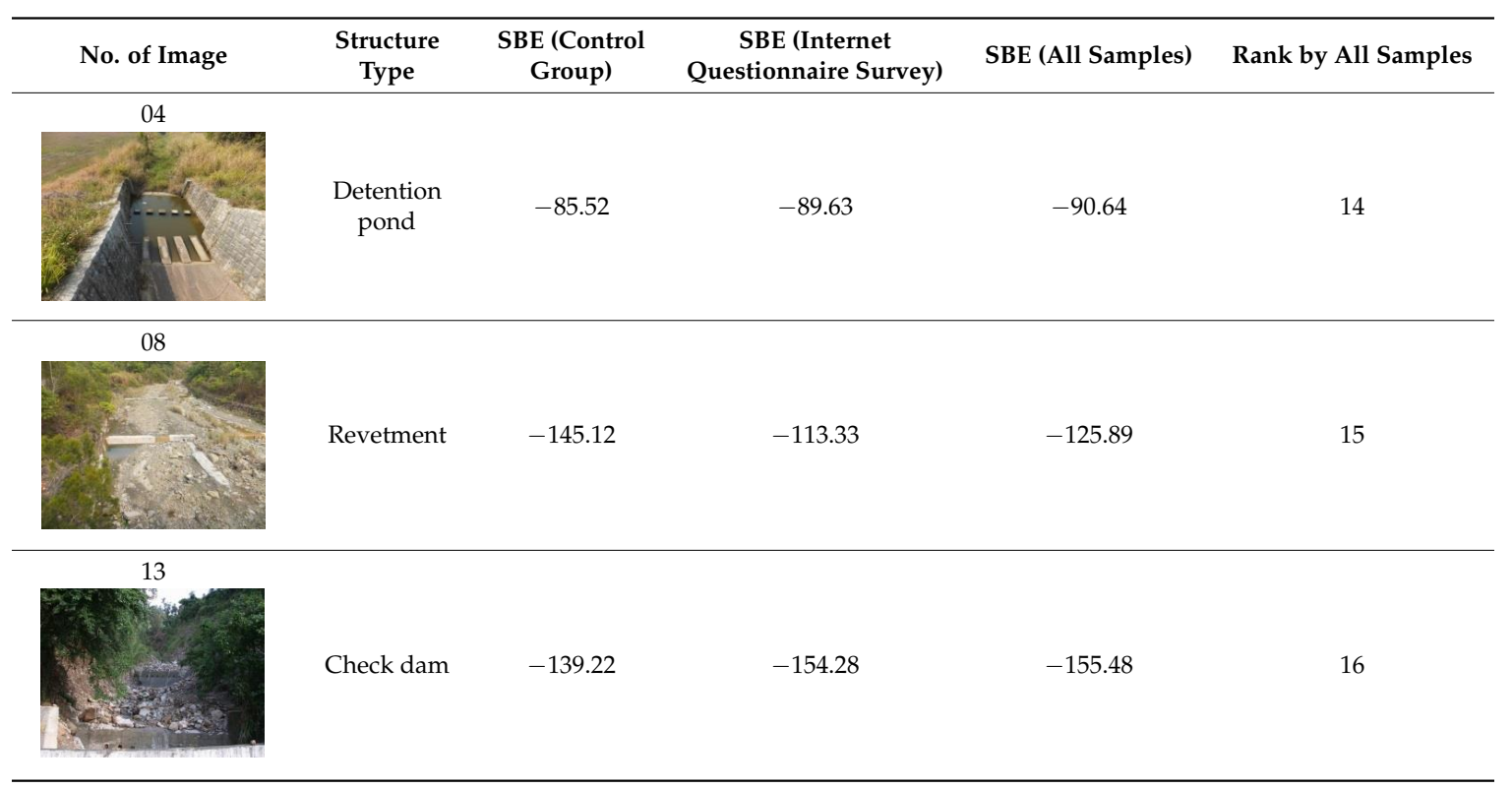

Regarding the top three pictures, with the SBE method in question 4 (Figure 3), the waterscape and the surrounding vegetation under the sun in the No. 11 image presented the highest richness. Interestingly, the vegetation in the picture integrating with the scene and the structure largely enhanced the richness of the picture in the subjects' eyes. For question 5, the No. 11 image also received the highest score among the three pictures (Figure 4). The ecological method was used in the picture, and natural materials of stones and vegetation were integrated with the environment. Apparently, the structure with the ecological method was preferred by the subjects. Similarly, No. 06 and 11 showed ecological methods (Figure 5) for question 6. People have largely enhanced the trust of ecological works from psychological experience.

Table 5. Paired sample $t$-test.

\begin{tabular}{ccc}
\hline & Control Group & Internet Questionnaire Survey \\
\hline average & 0 & 0.000625 \\
variance & $10,000.10629$ & 9999.774353 \\
No. of observation & 16 & 16 \\
Pearson correlation coefficient & 0.93055009 & \\
Assumed average difference & 0 & \\
Degree of freedom & 15 & \\
$t$ statistics & $-6.70796 \times 10^{-5}$ & \\
$P(T \leq t)$ one-tailed & 0.499973681 & \\
Critical value: one-tailed & 1.753050356 & \\
$P(T \leq t)$ two-tailed & 0.999947362 & \\
\hline
\end{tabular}




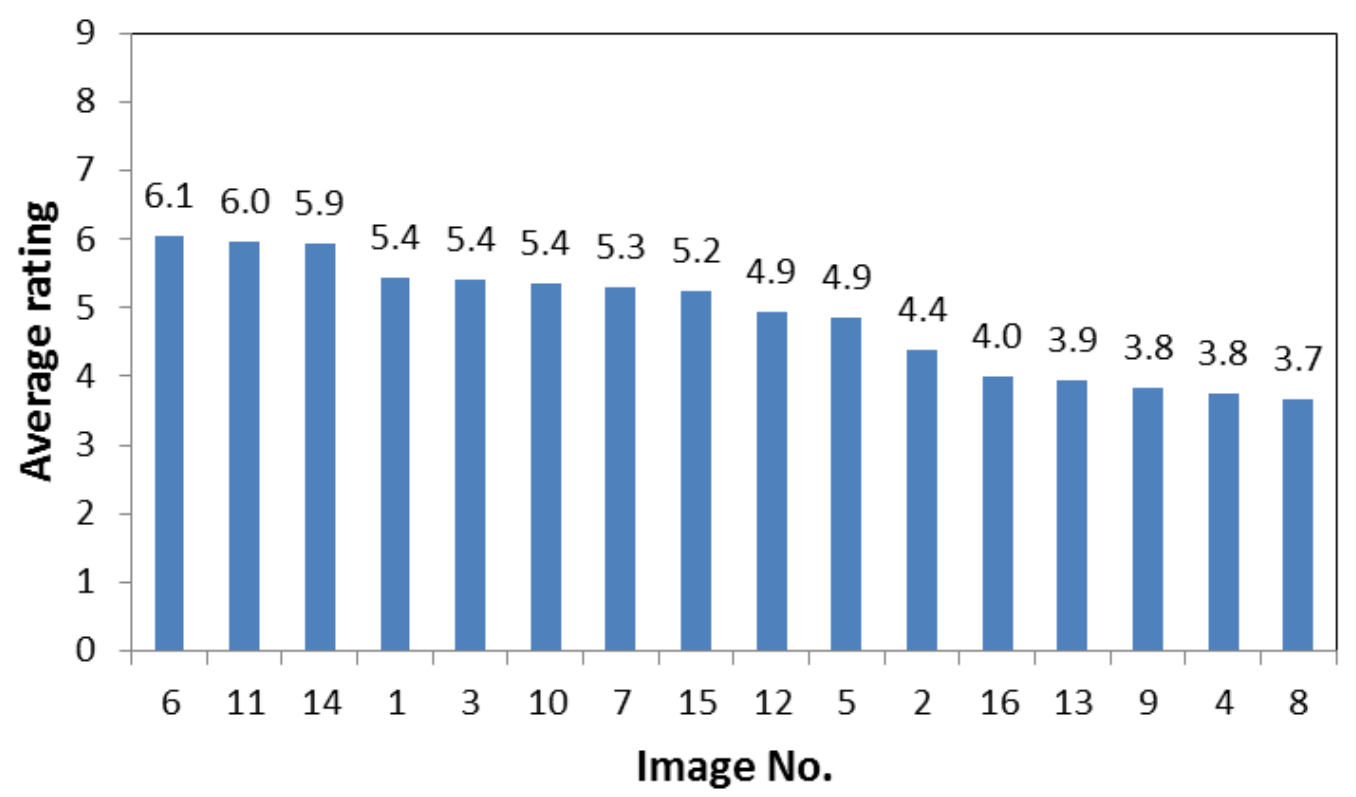

Figure 1. Average rating for question 2: integration of the structure in the picture with the natural environment

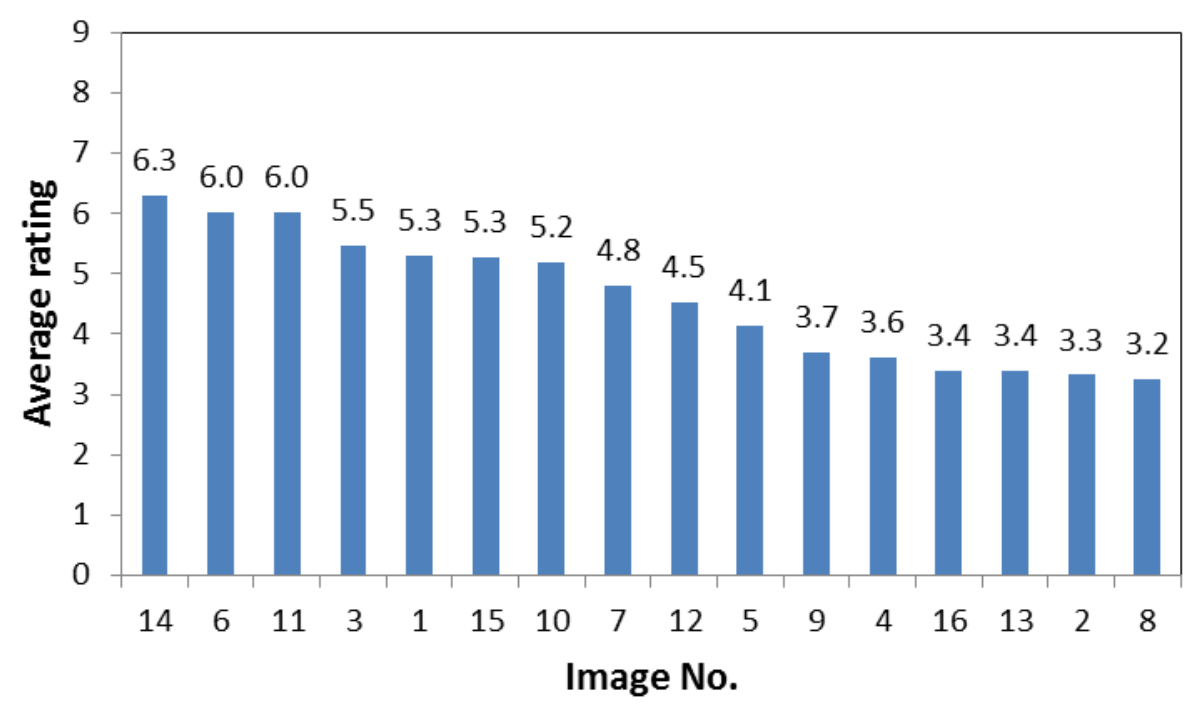

Figure 2. Average rating for question 3: preference for the waterscape in the picture.

Nonetheless, No. 13, 08, and 04 were the bottom three images in the SBE evaluation. The former two showed soil and water conservation engineering with the traditional method and were covered by soil and sand after the disaster. Many irregular stones and concrete structures resulted in the disharmony of the pictures. In contrast, No. 04 was a settling basin. Although it was well-maintained, a large amount of concrete materials and withered vegetation reduced the landscape assessment result. The top three pictures were mainly ecological and groundsill works with a rich waterscape. Vegetation is the common landscape in the slopeland, and different vegetations in the forest would exhibit obvious differences in scenic aesthetics. The effect of different vegetations would be reduced when the structure and the waterscape appear at the same time. In this case, the waterscape will present the largest effect on scenic aesthetics, followed by vegetation, structure volume, and shape. 


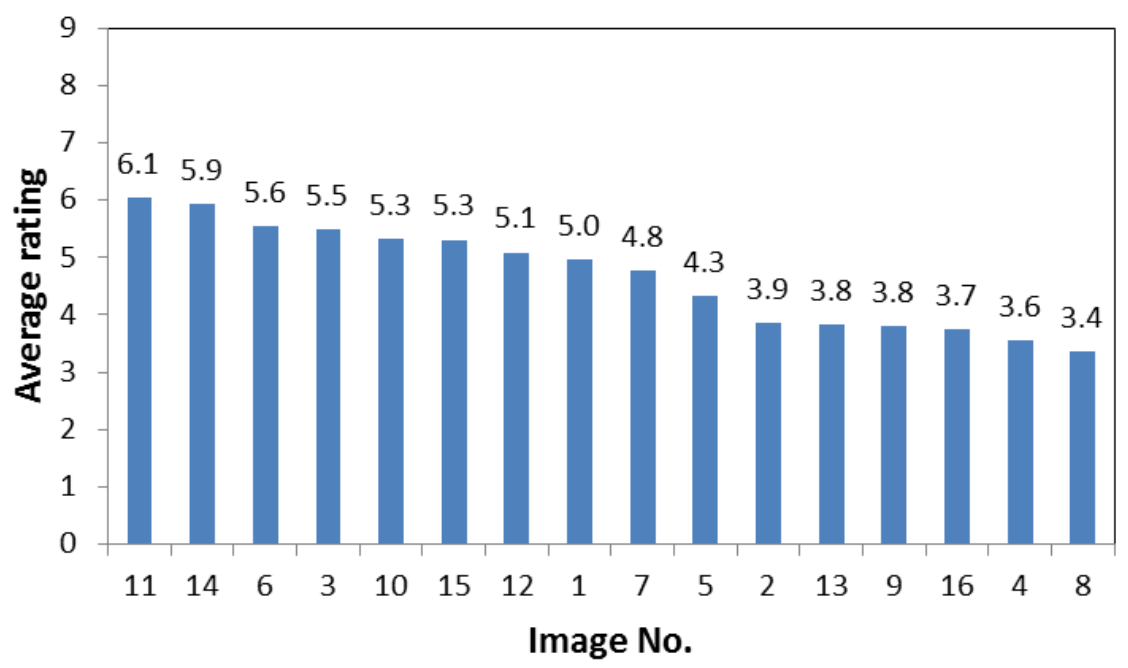

Figure 3. Average rating for question 4: visual richness of the pictures.

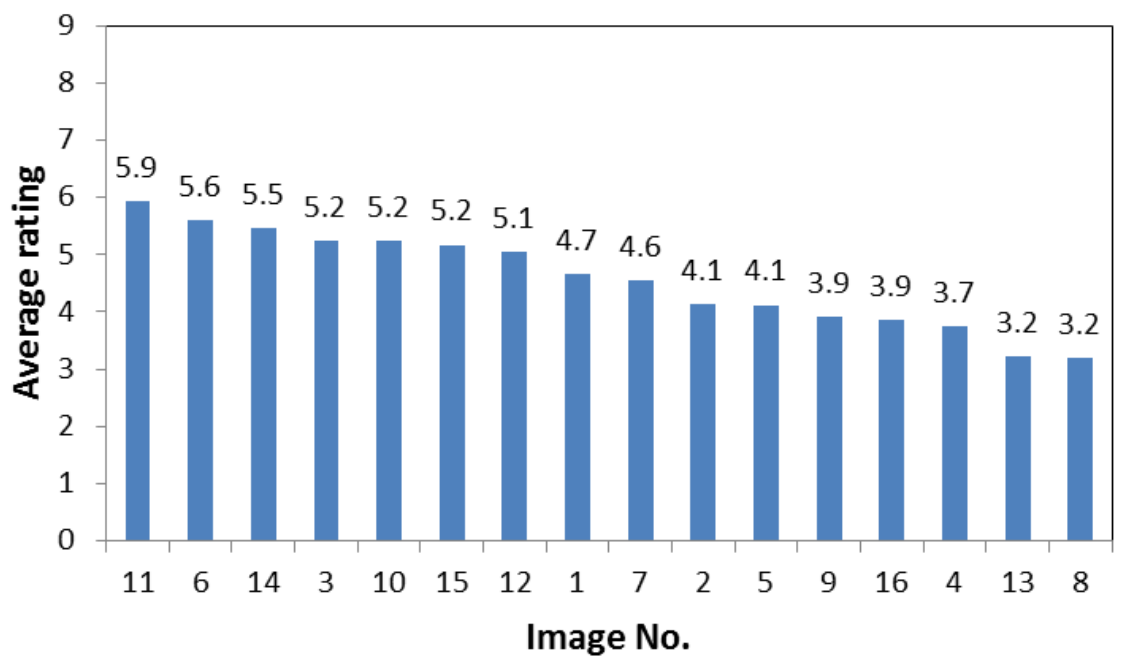

Figure 4. Average rating for question 5: preference for the structure shape in the picture.

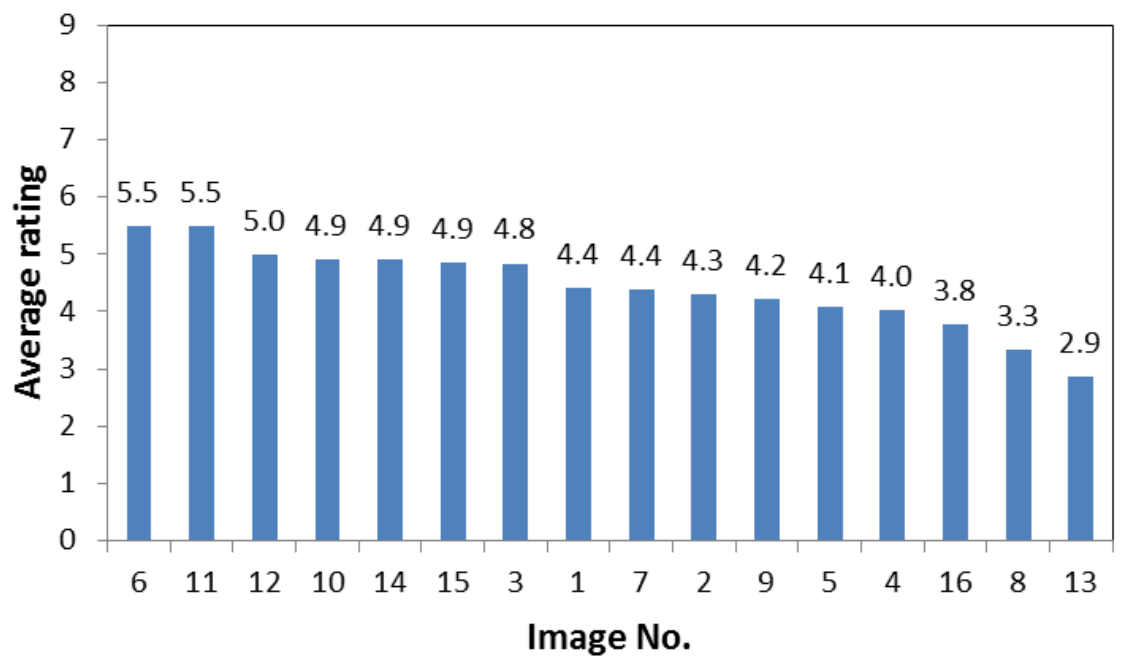

Figure 5. Average rating for question 6: perceived safety of structure in the picture. 


\section{Conclusions}

In comparison with buildings and bridges, both safety and aesthetic design must also be considered. A censorship even exists to take care of both. Nevertheless, soil and water conservation engineering is in natural locations; hence, landscape assessment should be considered to maintain the beauty of the natural environment. Aesthetics has not been considered in the soil and water conservation engineering design in Taiwan; therefore, no principle is being followed for landscape or aesthetic design. The engineering structure is often not visually integrated with the environmental landscape. The design integrating soil and water conservation engineering with natural background is discussed herein with the literature review, research method discussion, and case study as well as the assumption of the integration of engineering structure into the environment for the basic requirement for aesthetic design $[25,43]$.

The SBE method in psychophysics was applied to complete 51 copies of questionnaires and 105 copies of Internet questionnaires as the control group. After the analysis, the waterscape flow, vegetation size, and structure volume in pictures would affect the public overall scenic aesthetics. This study indicated that the waterscape and the rich flowing expression are the most important factors that would enhance the overall scenic beauty. Ecological engineering structures with natural materials and vegetation are often accepted by the public. A large number of irregular stones and concrete structures have caused discomfort in the picture and generally reduced the scenic beauty. These results will be useful for engineers and designers.

The SBE evaluation, which requires a large amount of questionnaire surveys for each evaluated target, is currently being completed. This study aims to do the landscape assessment of soil and water conservation engineering based on the SBE result. In the future, the images could be divided into close-up, medium, and long shots to calculate the proportion of landscape elements, which preceded regression with the SBE results for the experience prediction model of scenic aesthetics. More accurate results would be acquired for successive engineering design and application when more SBE samples are used.

Acknowledgments: This research was supported in part by a grant from Ministry of Science and Technology, Taiwan (NSC 102-2313-B-270-001).

Author Contributions: The text of this article was mainly written by Szu-Hsien Peng. Ke-Tsung Han participated the discussion and provided many valuable comments and suggestions.

Conflicts of Interest: The authors declare no conflict of interest.

\section{References}

1. Zobeck, T.M.; Schillinger, W.F. Soil and Water Conservation Advances in the United States; Soil Science Society of America: Madison, WI, USA, 2010.

2. SWCB (Soil and Water Conservation Bureau). Technical Manual for Soil and Water Conservation; Soil and Water Conservation Bureau, Council of Agriculture, Taiwan: Nantou, Taiwan, 2005. (In Chinese)

3. Wu, H.L.; Feng, Z.Y. Ecological engineering methods for soil and water conservation in Taiwan. Ecol. Eng. 2006, 28, 333-344. [CrossRef]

4. Buondonno, A.; Grilli, E.; Capra, G.F.; Glorioso, C.; Langella, A.; Leone, A.P.; Leone, N.; Odierna, P.; Vacca, S.; Vigliotti, R.C. Zeolitized tuffs in pedotechnique for the reclamation of abandoned quarries. A case study in the campania region (Italy). J. Environ. Manag. 2013, 122, 25-30. [CrossRef] [PubMed]

5. Aizawa, M. An Introduction to Hydroscape Engineering; Kajima Publishing: Tokyo, Japan, 2002. (In Japanese)

6. Arthur, L.M. Predicting scenic beauty of forest environments: Some empirical tests. For. Sci. 1977, 23, 151-160.

7. Brown, T.C.; Daniel, T.C. Modeling Forest Scenic Beauty: Concepts and Application to Ponderosa Pine; US Department of Agriculture, Forest Service, Rocky Mountain Forest and Range Experiment Station: Fort Collins, CO, USA, 1984.

8. Brown, T.C.; Daniel, T.C. Predicting scenic beauty of timber stands. For. Sci. 1986, 32, 471-487.

9. Buhyoff, G.J.; Wellman, J.D.; Harvey, H.; Fraser, R. Landscape architects' interpretations of people's landscape preferences. J. Environ. Manag. 1978, 6, 255-262. 
10. Mansourian, S. Governance and forest landscape restoration: A framework to support decision-making. J. Nat. Conserv. 2017, 37, 21-30. [CrossRef]

11. Miller, R.; Xiang, W.N. A knowledge-based GIS method for visual impact assessment in transmission line siting. In GIS LIS-International Conference; American Society for Photogrammetry and Remote Sensing: Baltimore, MD, USA, 1992; p. 577.

12. Müssner, R.; Plachter, H. Methodological standards for nature conservation: Case study landscape planning. J. Nat. Conserv. 2002, 10, 3-23. [CrossRef]

13. Lynch, K. The Image of the City; MIT Press: Cambridge, MA, USA, 1960; Volume 11.

14. McHarg, I.L.; Mumford, L. Design with Nature; American Museum of Natural History: New York, NY, USA, 1969.

15. Shafer, E.L.; Hamilton, J.E.; Schmidt, E.A. Natural landscape preferences: A predictive model. J. Leisure Res. 1969, 1, 1. [CrossRef]

16. Jackson, J.B.; Zube, E.H. Landscapes: Selected writings of JB Jackson; Univ of Massachusetts Press: Amherst, MA, USA, 1970.

17. Appleton, J.H. The Experience of Landscape; John Wiley and Sons: New York, NY, USA, 1975.

18. Balling, J.D.; Falk, J.H. Development of visual preference for natural environments. Environ. Behav. 1982, 14, 5-28. [CrossRef]

19. Kaplan, S.; Kaplan, R. Cognition and Environment: Functioning in an Uncertain World; Praeger: New York, NY, USA, 1982.

20. Daniel, T.C.; Vining, J. Methodological issues in the assessment of landscape quality. In Behavior and the Natural Environment; Springer: Berlin, Germany, 1983; pp. 39-84.

21. Gobster, P.H.; Chenoweth, R.E. The dimensions of aesthetic preference: A quantitative analysis. J. Environ. Manag. 1989, 29, 47-72.

22. Kaplan, R.; Kaplan, S. The Experience of Nature: A Psychological Perspective; CUP Archive: Cambridge, UK, 1989.

23. Zube, E.H. Themes in landscape assessment theory. Landsc. J. 1984, 3, 104-110. [CrossRef]

24. Zube, E.H.; Sell, J.L.; Taylor, J.G. Landscape perception: Research, application and theory. Landsc. Plan. 1982, 9, 1-33. [CrossRef]

25. Lin, H.C.; Peng, S.H.; Chen, S.C. Scenic beauty estimation of soil and water conservation engineering constructions on the slopeland. J. Soil Water Conserv. 2013, 45, 831-846. (In Chinese)

26. Ariso-Campa, A. Forest (Text) Uses: Assessing Semiotic Dimensions of Visual Landscapes; State University of New York: New York, NY, USA, 1991.

27. Penning-Rowsell, E.C. Fluctuating fortunes in gauging landscape value. Prog. Hum. Geogr. 1981, 5, $25-41$.

28. Litton, R.B. Forest Landscape Description and Inventories: A Basis for Land Planning and Design; Pacific Southwest Forest and Range Experiment Station, US Department of Agriculture: Washington, DC, USA, 1968.

29. Kaplan, S.; Kaplan, R.; Wendt, J.S. Rated preference and complexity for natural and urban visual material. Percept. Psychophys. 1972, 12, 354-356. [CrossRef]

30. Daniel, T.C.; Boster, R.S. Measuring Landscape Esthetics: The Scenic Beauty Estimation Method; Rocky Mountain Forest and Range Experiment Station: Fort Collins, CO, USA, 1976.

31. Peng, S.H.; Tang, C. Blending the analytic hierarchy process and fuzzy logical systems in scenic beauty assessment of check dams in streams. Water 2015, 7, 6983-6998. [CrossRef]

32. Cicchetti, C.J. A multivariate statistical analysis of wilderness users in the United States. Nat. Environ. Stud. Theor. Appl. Anal. 1972, 142-170.

33. Taylor, S.T. Examination of Viewer Perceptions and Preferences When Exposed to Naturally Occurring Aesthetic Scenes; Texas A\&M University: College Station, TX, USA, 1994.

34. Anderson, L.M.; Schroeder, H.W. Application of wildland scenic assessment methods to the urban landscape. Landsc. Plan. 1983, 10, 219-237. [CrossRef]

35. Schroeder, H.W.; Daniel, T.C. Predicting the scenic quality of forest road corridors. Environ. Behav. 1980, 12, 349-366. [CrossRef]

36. Ozkan, U.Y. Assessment of visual landscape quality using IKONOS imagery. Environ. Monit. Assess. 2014, 186, 4067-4080. [CrossRef] [PubMed]

37. Brown, T.C.; Daniel, T.C. Scaling of Ratings: Concepts and Methods; USDA Forest Service, Rocky Mountain Forest and Range Experiment Station: Fort Collins, CO, USA, 1990; Volume 293. 
38. Brown, T.C.; Daniel, T.C.; Schroeder, H.W.; Brink, G.E. Analysis of Ratings: A Guide to RMRATE; US Department of Agriculture, Forest Service, Rocky Mountain Forest and Range Experiment Station: Fort Collins, CO, USA, 1990.

39. Bulut, Z.; Yilmaz, H. Determination of waterscape beauties through visual quality assessment method. Environ. Monit. Assess. 2009, 154, 459. [CrossRef] [PubMed]

40. Aizawa, M. The texture of falling water, landscape, and culture of Japan. NAGARE Jpn. Soc. Fluid Mech. 2004, 23, 69-78. (In Japanse)

41. Manfrin, A.; Bombi, P.; Traversetti, L.; Larsen, S.; Scalici, M. A landscape-based predictive approach for running water quality assessment: A mediterranean case study. J. Nat. Conserv. 2016, 30, 27-31. [CrossRef]

42. Brown, T.C.; Daniel, T.C. Landscape aesthetics of riparian environments: Relationship of flow quantity to scenic quality along a wild and scenic river. Water Res. Res. 1991, 27, 1787-1795. [CrossRef]

43. Chen, S.Y.; Lin, J.Y. Developing a simplified river landscape assessment model: Examples from the Chungkang and Touchien Rivers, Taiwan. Environ. Monit. Assess. 2007, 127, 489-502. [CrossRef]

(C) 2018 by the authors. Licensee MDPI, Basel, Switzerland. This article is an open access article distributed under the terms and conditions of the Creative Commons Attribution (CC BY) license (http:// creativecommons.org/licenses/by/4.0/). 